Article

\title{
Evaluation of African-Bred Maize Germplasm Lines for Resistance to Aflatoxin Accumulation
}

\author{
Robert L. Brown ${ }^{1, *, \dagger}$, W. Paul Williams ${ }^{2,+}$, Gary L. Windham ${ }^{2, \dagger}$, Abebe Menkir $^{3, \dagger}$ and \\ Zhi-Yuan Chen ${ }^{4,+}$ \\ 1 United States Department of Agriculture, Agricultural Research Service, \\ Food and Feed Safety Research Unit, Southern Regional Research Center, New Orleans, LA 70124, USA \\ 2 USDA, ARS, Corn Host Plant Resistance Research Unit, Mississippi State, MS 39762-9555, USA; \\ paul.williams@ars.usda.gov (W.P.W.); gary.windham@ars.usda.gov (G.L.W.) \\ 3 International Institute of Tropical Agriculture, Oyo Rd., Ibadan PMB 5320, Nigeria; a.menkir@cgiar.org \\ 4 Department of Plant Pathology and Crop Physiology, LSU Agricultural Center, Baton Rouge, LA 70803, \\ USA; zchen@agcenter.lsu.edu \\ * Correspondence: robert.brown@ars.usda.gov; Tel.: +1-504-286-4359; Fax: +1-504-286-4419 \\ + These authors contributed equally to this work.
}

Academic Editors: Diego Rubiales, Maria Carlota Vaz Patto and Elena Prats

Received: 15 March 2016; Accepted: 7 April 2016; Published: 15 April 2016

\begin{abstract}
Aflatoxins, produced by the fungus Aspergillus flavus, contaminate maize grain and threaten human food and feed safety. Plant resistance is considered the best strategy for reducing aflatoxin accumulation. Six maize germplasm lines, TZAR101-TZAR106, were released by the International Institute of Tropical Agriculture-Southern Regional Research Center (IITA-SRRC) maize breeding collaboration for use in African National Programs and U.S. maize breeding programs. The present investigation was conducted to evaluate aflatoxin reduction by these lines in a U.S. environment. As germplasm lines, resistance was demonstrated by the lines tested in 2010 and 2014 trials. In 2010, TZAR106 was among the lines with the lowest toxin accumulation, and in 2014, along with TZAR102, supported low aflatoxin. When evaluated as single cross hybrids in 2012, 2013 and 2014, several crosses involving IITA-SRRC lines accumulated low toxin. In 2012, TZAR103 $\times$ HBA1 was one of 4 lines with the lowest concentration of aflatoxin. In 2014, five IITA-SRRC hybrids were among the lowest with TZAR102 $\times$ Va35 and TZAR102 $\times$ LH132 being the two lowest. Results demonstrate significant aflatoxin reduction by IITA-SRRC lines in a U.S. aflatoxin-conducive environment (at Mississippi State University). Further testing in different locations and environments is needed to further evaluate the potential usefulness of these germplasm lines.
\end{abstract}

Keywords: aflatoxin; host resistance; breeding; field trials

\section{Introduction}

The International Institute of Tropical Agriculture (IITA) in Ibadan, Nigeria, has a collaborative breeding project with the Southern Regional Research Center (SRRC) of the United States Department of Agriculture-Agricultural Research Service (USDA-ARS) located in New Orleans, LA, to develop maize germplasm with resistance to aflatoxin contamination (as summarized in [1]) for use by the National Programs in Central and West Africa and aflatoxin-resistance breeding programs in the U.S. Both the IITA and SRRC have invested considerable resources and effort to combat the problem of Aspergillus ear rot and the associated aflatoxin contamination in maize. The IITA has hot spot locations for evaluating its breeding materials under naturally occurring severe disease pressure and continually selects promising materials based on visual assessment for reduced levels of ear rot infection caused by one or more fungal pathogens. Over the years, the IITA developed an array of maize inbred lines with desirable agronomic traits, good husk cover, reduced ear rots, and stress tolerance from diverse 
sources of germplasm. These lines may possess alleles for resistance to aflatoxin contamination and other mycotoxins that can be assessed by researchers in the U.S. [1].

A quick and efficient maize kernel-screening assay (KSA) for evaluating resistance to aflatoxin production in a large number of genotypes was developed at the SRRC [2,3]. Laboratory-based KSA can be used as a pre-screening tool in a resistance-breeding program [3]. The SRRC also has the state-of-the-art proteomics technology that has been employed to identify and characterize kernel resistance-associated proteins (RAPs) [4,5]. In 1998, these mutually beneficial strengths of the two institutions prompted a formal research collaboration that brought together complementary research efforts on elimination of aflatoxin contamination in maize [1].

In the IITA-SRRC breeding collaboration, KSA was first used to evaluate aflatoxin accumulation in diverse elite inbred lines selected at IITA [6]. Seed of 76 inbred lines selected for moderate to high levels of resistance to ear rot caused by Aspergillus, Botrydiplodia, Diplodia, Fusarium, and/or Macropomina in the forest zone and mid-altitudes of West and Central Africa were sent by the IITA to the SRRC laboratory for aflatoxin screening [6]. In this evaluation, 18 inbred lines were identified as accumulating aflatoxin levels as low as or lower than the best resistant lines available in the U.S. Further studies involving some of these lines showed that their kernel protein profiles were different from those observed in selected U.S. lines [6,7], suggesting that the potential exists to identify novel traits in IITA lines. The resistant U.S. genotypes and inbred lines from the IITA, selected after being screened with the KSA, provided the genetic material for selecting parental lines for crosses in the resistance-breeding project $[1,8]$.

The pedigree and backcross breeding methods have been extensively used to develop lines with new combinations of agronomic traits and resistance to diseases. The IITA-SRRC project aimed to combine resistance of selected lines from the IITA with aflatoxin-resistance in inbred lines from the U.S. to develop improved inbred lines with desirable agronomic traits (as summarized in [1]). To achieve this objective, five elite IITA tropical inbred lines selected by the KSA [6], Babangoyo, KU1414-SR, 1368, 4001, and 9450, were crossed to eight aflatoxin-resistant U.S. lines: B73/Tex6, C12, GT-MAS:gk, MI82, Mo 17/Tex6, Mp420, Oh516, and T115 [3,9] to form 16 F1 crosses. A backcross (BC1) was made to each $\mathrm{F} 1$ cross using the respective genotype from the U.S. as a recurrent parent [8]. As measurement of aflatoxin produced by A. flavus in maize is a relatively tedious and expensive procedure, assessment of aflatoxin production was, thus, deferred until homozygous lines (S4) were developed with selection for agronomic traits and resistance to diseases during the early stages of inbreeding. At each stage of inbreeding, visual selection within and among lines was made on the basis of synchrony between pollen shed and silking, low ear placement, well-filled ears and resistance to lodging and diseases, including Puccinia polysora rust, Bipolaris maydis blight, and Curvularia lunata leaf spot, under naturally occurring disease pressure at Ibadan, Nigeria. The best lines at this stage were screened by the KSA for aflatoxin accumulation and those accumulating low levels of aflatoxin were then screened in the field for resistance at Ibadan. The best inbred lines that combined desirable agronomic traits with consistently low levels of aflatoxin in the laboratory and in the field were then selected for release as sources of genes for resistance to aflatoxin production. The six inbred lines selected for resistance to aflatoxin contamination were registered and released at S8 to S10 stages of inbreeding [10].

The six released germplasm lines were derived from biparental crosses and backcross populations involving tropical elite African inbred lines (1368, 4001, and KU1414-SR) from the IITA [11] with some levels of resistance to aflatoxin production [6] and U.S. inbred lines GT-MAS:gk, MI82, and Mp420, with proven resistance to aflatoxin contamination $[2,3,12,13]$ as parents. TZAR101 was derived from a cross of 1368 to GT-MAS:gk, while TZAR102 and TZAR103 were extracted from a cross of the same tropical inbred line (1368) to MI82. TZAR104 was extracted from a backcross involving GT-MAS:gk as a recurrent parent and KU1414-SR as a nonrecurrent parent. TZAR105 and TZAR106 were developed from a backcross involving Mp420 as a recurrent parent and 4001 as a nonrecurrent parent. TZAR102 and TZAR103 have white kernels, while the remaining four lines have yellow kernels, with all of them showing flint kernel texture [10]. 


\section{Results}

To facilitate evaluation of the aflatoxin-reduction potential of the IITA-SRRC lines, observations were made in comparison to other known aflatoxin-resistant releases also tested in these trials: Mp 420 [13], Mp313E [14], Mp 715 [15], Mp717 [16], Mp 718 [17], Mp719 [17] (Mp lines developed at ARS-Mississippi State University), and T115 [9]. Five IITA-SRRC germplasm lines were screened for aflatoxin accumulation levels for the first time in the U.S. in 2010 against 18 other maize inbred lines (Table 1). TZAR105 was not tested due to lack of seed. Mean aflatoxin accumulation ranged from $18,070 \mathrm{ng} / \mathrm{g}$ for SC212M to a low of $25 \mathrm{ng} / \mathrm{g}$ for Mp715. TZAR106 was numerically lowest in accumulation at $91 \mathrm{ng} / \mathrm{g}$, among the five IITA-SRRC lines and was not significantly different from Mp715 nor from well-known aflatoxin-resistant inbred Mp313E, but accumulated significantly less aflatoxin than Mp717 and Mp420. TZAR106 while numerically lower in aflatoxin accumulation than TZAR102, 103, 104 and 101 (265-730 ng/g), also was not significantly different in accumulation from these lines. TZAR 103, TZAR102 and TZAR104 supported numerically less aflatoxin than Mp420 (617 ng/g) and more than Mp717 (232 ng/g) although TZAR lines, 101, 102, 103, and 104 were not significantly different in aflatoxin levels supported by Mp717 and Mp420.

Table 1. Aflatoxin accumulation in germplasm lines evaluated at Mississippi State in 2010.

\begin{tabular}{ccc}
\hline & \multicolumn{2}{c}{${\text { Aflatoxin } \mathbf{( n g} / \mathbf{g})^{\dagger}}^{\dagger}$} \\
\hline Line & Ln $\mathbf{y}+\mathbf{1})$ & Geometric Mean \\
\hline SC212M & 9.80 & 18070 \\
B73 & 7.73 & 2273 \\
Tx114 & 7.57 & 1945 \\
MI82 & 7.30 & 1477 \\
Mp04:115 & 6.94 & 1035 \\
Mp494 & 6.81 & 901 \\
Va35 & 6.67 & 791 \\
TZAR101 & 6.59 & 730 \\
Mp420 & 6.60 & 617 \\
TI73 & 6.26 & 525 \\
TZAR104 & 5.89 & 360 \\
TZAR102 & 6.11 & 290 \\
TZAR103 & 5.58 & 265 \\
Mp717 & 5.45 & 232 \\
Mp317 & 5.07 & 159 \\
Mp09-10:363 & 4.88 & 130 \\
Mp04:97 & 4.81 & 121 \\
Mp04:87 & 4.72 & 111 \\
TZAR106 & 4.52 & 91 \\
Mp313E & 4.52 & 91 \\
Mp09:50 & 4.36 & 77 \\
Mp04:110 & 4.29 & 72 \\
Mp715 & 3.30 & 25 \\
LSD (0.05) & 2.09 & \\
\hline
\end{tabular}

\footnotetext{
† Plot means for aflatoxin concentration were transformed $(\operatorname{Ln}(y+1)$, where $y=$ concentration of aflatoxin in a sample) before statistical analysis. Geometric means were calculated by reverse transformation of logarithmic means back to the original units of measure.
}

When 51 hybrids, including ones created with TZAR germplasm lines, were evaluated in 2012, aflatoxin levels ranged from 1,539 $\mathrm{ng} / \mathrm{g}$ for B73 $\times$ CML11 to $11 \mathrm{ng} / \mathrm{g}$ for B73 $\times(((\mathrm{Mp} 494 \times \mathrm{Mp} 717)$ $\times(\mathrm{Mp} 313 \mathrm{E} \times \mathrm{Mp} 715))-\mathrm{B}-10-5-1-1)$ (Table 2). TZAR $\times$ HBA1 with $35 \mathrm{ng} / \mathrm{g}$, accumulated the lowest among the TZAR crosses and was among the four lines with the lowest concentration of aflatoxin in this trial; it was not significantly different from B73 $\times(((\mathrm{Mp} 494 \times \mathrm{Mp} 717) \times(\mathrm{Mp} 313 \mathrm{E} \times \mathrm{Mp}$ 715))-B-10-5-1-1). TZAR103 $\times 740$, also accumulated a relatively low amount of aflatoxin $(139 \mathrm{ng} / \mathrm{g})$, and was not significantly different from crosses involving B73 with known resistant lines, Mp717, 
Mp719, Mp313E and Mp420. TZAR103 $\times 740$ was also numerically low in aflatoxin concentration $(139 \mathrm{ng} / \mathrm{g})$, but not significantly different from TZAR106 $\times$ HBA1, TZAR102 $\times 740$, TZAR104 $\times$ HBA1, TZAR101 $\times$ HBA1 and TZAR106 $\times 740$ (ranging from 262-336 ng/g). TZAR101 $\times$ PHW79 accumulated a high concentration of aflatoxin and was not significantly different from B73 $\times$ CML11 which had the highest aflatoxin concentration.

Table 2. Aflatoxin accumulation in single-cross hybrids evaluated at Mississippi State in 2012.

\begin{tabular}{|c|c|c|}
\hline Pedigree & $\operatorname{Ln}(y+1)$ & $\begin{array}{c}\text { Aflatoxin }{ }^{\dagger} \text { Geometric } \\
\text { Mean (ng/g) }\end{array}$ \\
\hline B73 × CML 11 & 7.34 & 1539 \\
\hline $\mathrm{B} 73 \times \mathrm{SC} 212 \mathrm{M}$ & 6.83 & 921 \\
\hline TZAR $101 \times$ PHW 79 & 6.76 & 865 \\
\hline $\mathrm{B} 73 \times(((\mathrm{Mp} 494 \times \mathrm{Mp} 717) \times(\mathrm{Mp} 313 \mathrm{E} \times \mathrm{Mp} 715))-\mathrm{B}-14-2-1-2)$ & 6.69 & 803 \\
\hline B73 × NC 388 & 6.64 & 762 \\
\hline $\mathrm{B} 73 \times \mathrm{Mp}$ 04:110 & 6.56 & 703 \\
\hline B73 $\times$ Va 35 & 6.33 & 560 \\
\hline $\mathrm{B} 73 \times \mathrm{T} 173$ & 6.25 & 517 \\
\hline $\mathrm{B} 73 \times \mathrm{T} \times 114$ & 6.23 & 505 \\
\hline B73 $\times$ CML 311 & 6.21 & 495 \\
\hline $\mathrm{B} 73 \times \mathrm{CML} 176$ & 6.08 & 435 \\
\hline $\mathrm{B} 73 \times \mathrm{Mp} 718$ & 6.06 & 429 \\
\hline B73 $\times$ CML 69 & 5.94 & 378 \\
\hline B73 $\times$ SC 229 & 5.90 & 363 \\
\hline B73 $\times$ GA 209 & 5.89 & 361 \\
\hline $\mathrm{B} 73 \times \mathrm{Mp} 10: 120$ & 5.84 & 344 \\
\hline TZAR $106 \times 740$ & 5.82 & 336 \\
\hline $\mathrm{B} 73 \times \mathrm{Mp}$ 10:135 & 5.81 & 331 \\
\hline $\mathrm{B} 73 \times \mathrm{Mp} 711$ & 5.80 & 329 \\
\hline TZAR $101 \times$ HBA 1 & 5.77 & 319 \\
\hline B73 × CML 343 & 5.72 & 303 \\
\hline $\mathrm{B} 73 \times \mathrm{Mo} 17$ & 5.70 & 298 \\
\hline TZAR $104 \times$ HBA 1 & 5.69 & 296 \\
\hline $\mathrm{B} 73 \times(((\mathrm{Mp} 494 \times \mathrm{Mp} 717) \times(\mathrm{Mp} 313 \mathrm{E} \times \mathrm{Mp} 715))-\mathrm{B}-14-2-1-1)$ & 5.68 & 291 \\
\hline B73 $\times$ Ki 3 & 5.65 & 284 \\
\hline TZAR $102 \times 740$ & 5.65 & 283 \\
\hline B73 $\times$ Tzi 18 & 5.65 & 283 \\
\hline TZAR $106 \times$ HBA 1 & 5.57 & 262 \\
\hline B73 × CML 108 & 5.53 & 251 \\
\hline $\mathrm{B} 73 \times \mathrm{Mp} 420$ & 5.47 & 236 \\
\hline $\mathrm{B} 73 \times(((\mathrm{Mp} 494 \times \mathrm{Mp} 717) \times(\mathrm{Mp} 313 \mathrm{E} \times \mathrm{Mp} 715))-\mathrm{B}-14-3-1-1)$ & 5.40 & 220 \\
\hline $\mathrm{B} 73 \times(((\mathrm{Mp} 494 \times \mathrm{Mp} 717) \times(\mathrm{Mp} 313 \mathrm{E} \times \mathrm{Mp} 715))-\mathrm{B}-14-3-1-2)$ & 5.28 & 195 \\
\hline B73 $\times$ Mp 10:109 & 5.17 & 174 \\
\hline $\mathrm{B} 73 \times(((\mathrm{Mp} 494 \times \mathrm{Mp} 717) \times(\mathrm{Mp} 313 \mathrm{E} \times \mathrm{Mp} 715))-\mathrm{B}-10-5-1-1)$ & 5.08 & 161 \\
\hline $\mathrm{B} 73 \times \mathrm{Mp} 313 \mathrm{E}$ & 5.04 & 153 \\
\hline TZAR $103 \times 740$ & 4.94 & 139 \\
\hline $\mathrm{B} 73 \times \mathrm{Mp} 719$ & 4.88 & 130 \\
\hline $\mathrm{B} 73 \times \mathrm{Mp} 10: 127$ & 4.77 & 117 \\
\hline $\mathrm{B} 73 \times \mathrm{Mp} 717$ & 4.75 & 115 \\
\hline $\mathrm{B} 73 \times(((\mathrm{Mp} 494 \times \mathrm{Mp} 717) \times(\mathrm{Mp} 313 \mathrm{E} \times \mathrm{Mp} 715))-\mathrm{B}-5-3-1-1)$ & 4.64 & 103 \\
\hline $\mathrm{B} 73 \times(((\mathrm{Mp} 494 \times \mathrm{Mp} 717) \times(\mathrm{Mp} 313 \mathrm{E} \times \mathrm{Mp} 715))-\mathrm{B}-5-3-1-2)$ & 4.57 & 95 \\
\hline B73 $\times$ Tzi 10 & 4.52 & 90 \\
\hline $\mathrm{B} 73 \times \mathrm{Mp}$ 10:111 & 4.46 & 85 \\
\hline $\mathrm{B} 73 \times \mathrm{Mp} 10: 127$ & 4.43 & 83 \\
\hline $\mathrm{B} 73 \times \mathrm{NC} 332$ & 4.34 & 76 \\
\hline $\mathrm{B} 73 \times \mathrm{SC} 76$ & 4.25 & 69 \\
\hline $\mathrm{B} 73 \times(((\mathrm{Mp} 494 \times \mathrm{Mp} 717) \times(\mathrm{Mp} 313 \mathrm{E} \times \mathrm{Mp} 715))-\mathrm{B}-3-1-1-1)$ & 3.92 & 49 \\
\hline TZAR $103 \times$ HBA 1 & 3.58 & 35 \\
\hline $\mathrm{B} 73 \times \mathrm{NC} 340$ & 3.26 & 25 \\
\hline B73 $\times$ CML 247 & 3.14 & 22 \\
\hline $\mathrm{B} 73 \times(((\mathrm{Mp} 494 \times \mathrm{Mp} 717) \times(\mathrm{Mp} 313 \mathrm{E} \times \mathrm{Mp} 715))-\mathrm{B}-10-5-1-1)$ & 2.49 & 11 \\
\hline $\operatorname{LSD}(0.05)$ & 1.33 & \\
\hline
\end{tabular}

${ }^{\dagger}$ Plot means for aflatoxin concentration were transformed $(\operatorname{Ln}(\mathrm{y}+1)$, where $\mathrm{y}=$ concentration of aflatoxin in a sample) before statistical analysis. Geometric means were calculated by reverse transformation of logarithmic means back to the original units of measure. 
Fifty-six single-cross hybrids, the majority involving susceptible line T173, were evaluated for aflatoxin accumulation in a trial in 2013, and aflatoxin levels ranged from a high of $491 \mathrm{ng} / \mathrm{g}$ for NC334 $\times$ T173 to a low of $1 \mathrm{ng} / \mathrm{g}$ for Mp313E $\times$ Mp494 (Table 3). The majority of the data in Table 3 was reported in a previous publication in a table that also reported aflatoxin values for inbreds that were crossed with T173 [18].The TZAR cross with the lowest numerical accumulation was TZAR106 $\times$ T173 with $27 \mathrm{ng} / \mathrm{g}$ which was significantly different from NC334 $\times$ T173, but not significantly different from crosses involving known resistant lines including Mp715 and Mp719. TZAR101 $\times$ T173 also accumulated relatively low levels of aflatoxin $(69 \mathrm{ng} / \mathrm{g})$ and was not significantly different from TZAR106 $\times$ T173. Levels of aflatoxin in T173 crosses involving TZAR103, TZAR104 and TZAR102 were not significantly different from the highest aflatoxin level in this trial, which was recorded for NC334 $\times$ T173.

Table 3. Aflatoxin accumulation in single cross hybrids evaluated at Mississippi State in 2013.

\begin{tabular}{|c|c|c|c|c|c|}
\hline Pedigree & $\begin{array}{l}\text { Aflatoxin ** } \\
\operatorname{Ln}(y+1)\end{array}$ & $\begin{array}{c}\text { Geometric } \\
\text { Mean (ng/g) }\end{array}$ & Pedigree & $\begin{array}{c}\text { Aflatoxin }^{+} \\
\text {Ln }(y+1)\end{array}$ & $\begin{array}{l}\text { Geometric } \\
\text { Mean ng/g }\end{array}$ \\
\hline NC $334 \times$ T 173 & 6.20 & 491 & CML $108 \times$ T 173 & 4.53 & 92 \\
\hline CML $311 \times$ T 173 & 6.13 & 460 & CML $226 \times$ T 173 & 4.42 & 82 \\
\hline Va $35 \times$ T 173 & 5.88 & 357 & Mp 10:127 × T 173 & 4.40 & 81 \\
\hline SC $212 \mathrm{M} \times \mathrm{T} 173$ & 5.83 & 339 & Mp $10: 109 \times$ T 173 & 4.32 & 74 \\
\hline PHW 79 × T 173 & 5.60 & 270 & $\mathrm{Mp} 718 \times \mathrm{T} 173$ & 4.30 & 72 \\
\hline A6 × T 173 & 5.55 & 257 & TZAR $101 \times$ T 173 & 4.24 & 69 \\
\hline SC $76 \times$ T 173 & 5.55 & 256 & Mp 10:111 × T 173 & 4.14 & 62 \\
\hline TZAR $102 \times$ T 173 & 5.45 & 232 & Hi $27 \times$ T 173 & 4.12 & 61 \\
\hline Mp $711 \times$ T 173 & 5.40 & 219 & Mp 07:153 × T 173 & 4.07 & 57 \\
\hline TZAR $104 \times$ T 173 & 5.37 & 213 & Mp10:117 × T173 & 4.02 & 55 \\
\hline CML $322 \times$ T 173 & 5.34 & 207 & CML $11 \times$ T 173 & 3.98 & 53 \\
\hline B $73 \times$ T 173 & 5.28 & 196 & GA $209 \times$ T 173 & 3.77 & 42 \\
\hline NC $298 \times$ T 173 & 5.05 & 155 & AAP $112 \times$ T 173 & 3.77 & 42 \\
\hline TZAR $105 \times$ T 173 & 5.01 & 148 & Mp 10:120 × T 173 & 3.72 & 40 \\
\hline Mp 10:113 × T 173 & 5.00 & 147 & Mp 10:127 × T 173 & 3.69 & 39 \\
\hline CML $343 \times$ T 173 & 4.85 & 126 & NC 340 × T 173 & 3.58 & 35 \\
\hline CML $45 \times$ T 173 & 4.83 & 124 & CML $264 \times$ T 173 & 3.45 & 31 \\
\hline Mp 10:131 × T 173 & 4.79 & 119 & Mp $717 \times$ T 173 & 3.44 & 30 \\
\hline AAP $239 \times$ T 173 & 4.74 & 114 & $\mathrm{Ki3} \times \mathrm{T} 173$ & 3.37 & 28 \\
\hline Tzi $18 \times$ T 173 & 4.67 & 106 & TZAR $106 \times$ T 173 & 3.33 & 27 \\
\hline NC $356 \times$ T 173 & 4.62 & 101 & Mp $705 \times$ T 173 & 3.32 & 27 \\
\hline \multirow[t]{3}{*}{ Tzi $8 \times$ T 173} & 4.62 & 100 & $\mathrm{Mp} 715 \times$ T 173 & 3.23 & 24 \\
\hline & & & CML $376 \times$ T 173 & 3.12 & 22 \\
\hline & & & NC $388 \times$ T 173 & 3.11 & 21 \\
\hline \multirow[t]{5}{*}{ Mp 313E × T 173} & 4.58 & 97 & Mp $494 \times$ Mp 717 & 2.85 & 16 \\
\hline & & & Mp $719 \times$ T 173 & 2.47 & 11 \\
\hline & & & Mp $494 \times$ Mp 719 & 1.87 & 5 \\
\hline & & & Mp 04:127 × T 173 & 1.81 & 5 \\
\hline & & & Mp 04:110 × T 173 & 1.76 & 5 \\
\hline \multirow[t]{4}{*}{ Mp 04:115 × T 173} & 4.56 & 95 & CML $247 \times$ T 173 & 1.75 & 5 \\
\hline & & & CML $348 \times$ T 173 & 1.50 & 3 \\
\hline & & & $\mathrm{Mp} 313 \mathrm{E} \times \mathrm{Mp} 494$ & 0.80 & 1 \\
\hline & & & $\operatorname{LSD}(0.05)$ & 1.68 & \\
\hline
\end{tabular}

${ }^{\dagger}$ Plot means for aflatoxin concentration were transformed $(\operatorname{Ln}(y+1)$, where $y=$ concentration of aflatoxin in a sample) before statistical analysis. Geometric means were calculated by reverse transformation of logarithmic means back to the original units of measure.

Aflatoxin accumulation in 36 germplasm lines, when evaluated in 2014, ranged from $5117 \mathrm{ng} / \mathrm{g}$ for SC212M to $2 \mathrm{ng} / \mathrm{g}$ for Mp717 (Table 4). The lowest aflatoxin concentration in the TZAR entries was for TZAR102 at $40 \mathrm{ng} / \mathrm{g}$, which differed significantly from Mp717 but not from Mp313E $(29 \mathrm{ng} / \mathrm{g})$. TZAR106 and TZAR103 accumulated relatively low levels of aflatoxin (73 and $163 \mathrm{ng} / \mathrm{g}$, respectively) and were not significantly different from TZAR102. Aflatoxin levels in TZAR102 as well as TZAR106 and TZAR103 were not significantly different from other known resistant lines including Mp718, Mp715, Mp719, Mp420, and T115. TZAR101 had a high concentration of aflatoxin at $960 \mathrm{ng} / \mathrm{g}$, but 
was significantly lower than SC212M and SC76, which accumulated the highest levels of aflatoxin in this trial.

Table 4. Aflatoxin accumulation in germplasm lines evaluated at Mississippi State in 2014.

\begin{tabular}{|c|c|c|}
\hline Germplasm Line & Aflatoxin $^{\dagger} \operatorname{Ln}(y+1)$ & Geometric Mean (ng/g) \\
\hline SC212M & 8.54 & 5117 \\
\hline SC76 & 7.11 & 1300 \\
\hline GA209 & 6.91 & 1004 \\
\hline Mo17 & 6.89 & 978 \\
\hline TZAR101 & 6.87 & 960 \\
\hline $\mathrm{T} 173$ & 6.39 & 594 \\
\hline B73 & 6.23 & 508 \\
\hline $\mathrm{Ab} 24 \mathrm{E}$ & 6.11 & 451 \\
\hline Mo18w & 5.79 & 325 \\
\hline Mp494 & 5.71 & 302 \\
\hline Va35 & 5.70 & 297 \\
\hline CML247 & 5.16 & 175 \\
\hline TZAR103 & 5.10 & 163 \\
\hline T115 & 5.05 & 155 \\
\hline CML322 & 5.02 & 151 \\
\hline Mp420 & 4.93 & 137 \\
\hline Mp719 & 4.45 & 85 \\
\hline Mp715 & 4.31 & 73 \\
\hline TZAR106 & 4.30 & 73 \\
\hline Mp10:127 & 4.16 & 63 \\
\hline Mp04:115 & 3.78 & 41 \\
\hline TZAR102 & 3.72 & 40 \\
\hline Mp10:135 & 3.71 & 40 \\
\hline Mp718 & 3.56 & 34 \\
\hline Mp10:131 & 3.50 & 32 \\
\hline Mp07:153 & 3.43 & 30 \\
\hline Mp313E & 3.40 & 29 \\
\hline Mp04:119 & 3.23 & 24 \\
\hline Mp04:110 & 2.76 & 15 \\
\hline Mp10:177 & 2.37 & 10 \\
\hline Mp10:113 & 2.31 & 9 \\
\hline Mp10:111 & 1.87 & 5 \\
\hline Mp10:120 & 1.82 & 5 \\
\hline Mp10:109 & 1.68 & 4 \\
\hline Mp10:107 & 1.19 & 2 \\
\hline Mp717 & 1.11 & 2 \\
\hline $\operatorname{LSD}(0.05)$ & 1.62 & \\
\hline
\end{tabular}

${ }^{\dagger}$ Plot means for aflatoxin concentration were transformed $(\operatorname{Ln}(y+1)$, where $y=$ concentration of aflatoxin in a sample) before statistical analysis. Geometric means were calculated by reverse transformation of logarithmic means back to the original units of measure.

Testcrosses involving TZAR germplasm lines were also evaluated in 2014, and aflatoxin levels ranged from $340 \mathrm{ng} / \mathrm{g}$ for TZAR104 $\times$ PHW79 to $2 \mathrm{ng} / \mathrm{g}$ for TZAR102 $\times$ Va35 (Table 5). TZAR102 $\times$ LH132, TZAR102 $\times$ PHW79, TZAR101 $\times$ LH132 and TZAR101 $\times$ Va35 also were among the lines with the lowest toxin levels $(4-8 \mathrm{ng} / \mathrm{g}$ ) and were also not significantly different from crosses involving known resistant inbred lines, Mp719, Mp313E, Mp494, Mp717 and Mp420. Testcrosses TZAR106 $\times$ LH132, TZAR102 $\times$ B73 and TZAR106 $\times$ B73 accumulated relatively low levels of aflatoxin (30-40 ng/g), but were significantly different from the group of TZAR testcrosses with the lowest aflatoxin accumulation. Aflatoxin concentrations in the remaining six TZAR entries ranged from $53 \mathrm{ng} / \mathrm{g}$ to $291 \mathrm{ng} / \mathrm{g}$ but were not significantly different from TZAR104 $\times$ PHW79, which accumulated the highest concentration of aflatoxin. 
Table 5. Aflatoxin accumulation in testcrosses evaluated at Mississippi State in 2014.

\begin{tabular}{|c|c|c|}
\hline Pedigree & Aflatoxin $^{+} \operatorname{Ln}(y+1)$ & Geometric Means (ng/g) \\
\hline TZAR104 × PHW79 & 5.99 & 340 \\
\hline TZAR104 × Va35 & 5.76 & 291 \\
\hline $\mathrm{T} 173 \times$ Va35 & 5.63 & 286 \\
\hline GA209 × B73 & 5.50 & 243 \\
\hline $\mathrm{Mp} 313 \mathrm{E} \times \mathrm{B} 73$ & 5.35 & 209 \\
\hline TZAR104 × B73 & 5.03 & 153 \\
\hline TZAR104 × LH132 & 4.74 & 113 \\
\hline TZAR101 × B73 & 4.49 & 88 \\
\hline Mp420 × LH132 & 4.48 & 87 \\
\hline $\mathrm{T} 173 \times \mathrm{B} 73$ & 4.25 & 69 \\
\hline TZAR106 × PHW79 & 4.24 & 68 \\
\hline PHW79 $\times$ B73 & 4.22 & 67 \\
\hline Mp313E × PHW79 & 4.20 & 66 \\
\hline CML108 $\times$ B73 & 4.07 & 57 \\
\hline TZAR101 × PHW79 & 3.99 & 53 \\
\hline Mp494 × B73 & 3.97 & 52 \\
\hline CML322 × PHW79 & 3.94 & 50 \\
\hline Mp715 × PHW79 & 3.74 & 41 \\
\hline TZAR106 × B73 & 3.71 & 40 \\
\hline TZAR102 × B73 & 3.53 & 33 \\
\hline TZAR106 × LH132 & 3.42 & 30 \\
\hline $\mathrm{Mp} 420 \times \mathrm{B} 73$ & 3.42 & 30 \\
\hline Mp313E $\times$ LH132 & 2.99 & 19 \\
\hline Mp717 × PHW79 & 2.95 & 18 \\
\hline Mp494 × PHW79 & 2.86 & 16 \\
\hline Mp313E × Va35 & 2.75 & 15 \\
\hline CML322 $\times$ B73 & 2.69 & 14 \\
\hline Va35 $\times$ B73 & 2.69 & 14 \\
\hline Mp719 × B73 & 2.66 & 13 \\
\hline PHW79 $\times$ LH132 & 2.62 & 13 \\
\hline CML108 $\times$ LH132 & 2.47 & 11 \\
\hline Va35 $\times$ LH132 & 2.29 & 9 \\
\hline TZAR101 $\times$ Va35 & 1.20 & 8 \\
\hline TZAR101 × LH132 & 1.96 & 6 \\
\hline TZAR102 $\times$ PHW79 & 1.94 & 6 \\
\hline CML108 × PHW79 & 1.91 & 6 \\
\hline $\mathrm{Mp} 717 \times$ Va35 & 1.90 & 6 \\
\hline Mp717 × B73 & 1.87 & 5 \\
\hline TZAR102 × LH132 & 1.54 & 4 \\
\hline TZAR102 × Va35 & 1.15 & 2 \\
\hline $\operatorname{LSD}(0.05)$ & 2.22 & \\
\hline
\end{tabular}

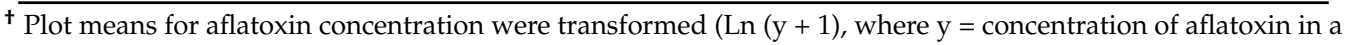
sample) before statistical analysis. Geometric means were calculated by reverse transformation of logarithmic means back to the original units of measure.

\section{Discussion}

One of the goals of the IITA-SRRC maize breeding collaboration was to develop inbred lines with aflatoxin resistance for use in National Programs of Central and West Africa. Thus far, TZAR101-TZAR106 have been sent to the National Programs of Nigeria, Ghana, Uganda and Ethiopia [19] In these programs IITA-SRRC lines are being used to create synthetic lines and hybrids. The other goal of the collaboration was to develop inbreds for use in aflatoxin-resistance breeding programs in the U.S. The present report documents several trials conducted in the U.S. at Mississippi State University to evaluate IITA-SRRC lines for resistance to aflatoxin accumulation.

When evaluated as germplasm lines, all IITA-SRRC lines demonstrated resistance in the 2010 and 2014 trials (TZAR105 was not tested in 2010; TZAR104 and TZAR105 were not tested in 2014). 
TZAR106 was equal to the best of all entries and was the lowest in aflatoxin accumulation among IITA-SRRC lines tested in 2010. TZAR106 along with TZAR102 were the best of the IITA-SRRC lines in 2014, while TZAR101 supported the most aflatoxin in both years. With all trials taking place in Mississippi and having several entries bred at and registered from Mississippi, comparisons of TZAR lines with established Mississippi resistant lines may provide a good glimpse as to the potential of the IITA-SRRC lines to serve as sources of aflatoxin-resistance. In 2010, TZAR106 was not significantly different from Mp313E and Mp715, and was among the lines with the lowest levels of aflatoxin accumulation, and was significantly lower than Mp717 and Mp420. In this trial, TZAR lines 103, 102, 104 and 101 were equivalent to Mp420 and Mp717. In 2014, TZAR106 and TZAR102 were equivalent to Mp718 and Mp313E, as well as Mp715, Mp719 and Mp420, while supporting significantly more aflatoxin than Mp717. It may be interesting that the pedigree of TZAR106 $((4001 \times$ Mp420 $) \times$ Mp420) is contributed to by Mp420.

The lowest accumulation of aflatoxin among IITA-SRRC lines involved in testcrosses varied in trials evaluated in 2012, 2013 and 2014. In 2012, TZAR103 $\times$ HBA1 was among the four testcrosses demonstrating the highest level of resistance in the trial. Other testcrosses involving TZAR106, 102, 104 and 101 showed good resistance as well. In the testcross trial of 2013 evaluating crosses involving T173, no TZAR derived crosses were among the best lines, however, two lines involving TZAR106 and 101 supported relatively low toxin levels. In the 2014 trial, the lowest accumulation of aflatoxin were in two testcrosses involving TZAR102; three other TZAR crosses involving TZAR102 and TZAR101were not significantly different from the two lowest. TZAR testcrosses compared favorably with crosses involving Mississippi inbred lines, Mp717, Mp719, Mp420, Mp715, Mp718 and Mp313E. Best results were observed with crosses TZAR $\times$ HBA1, TZAR102 $\times$ Va35, TZAR102 $\times$ LH132, TZAR $102 \times$ PHW79, TZAR101 $\times$ LH132 and TZAR101 $\times$ Va35.

\section{Experimental Section}

\subsection{Planting Dates and Experiments}

Multiple experiments to evaluate IITA-SRRC lines for aflatoxin accumulation were conducted at Mississippi State University (MSU). The 2010 germplasm line evaluation was planted on 30 April; the single cross hybrid test for 2012 was planted on 11 April; the single cross hybrid test for 2013 was planted on 14 May 2013; the germplasm line and testcross evaluations in 2014 were planted on 21 April 2014. The soil type for the experiments was a Leeper silty clay loam (fine, smectitic, non-acid, thermic Vertic Epiaquepts). Germplasm lines or hybrids were planted in single row plots that were $4 \mathrm{~m}$ long, spaced $0.97 \mathrm{~m}$ apart, and arranged in a randomized complete block design with four replications. Standard maize production practices were followed.

Seven days after silks had emerged from $50 \%$ of the plants in a plot, the primary ear of each plant was inoculated with Aspergillus flavus isolate NRRL 3357, which is known to produce aflatoxin in maize, using the side-needle technique [20]. Using a tree-marking gun fitted with a 14-gague needle, a 3.4-mL suspension containing $3 \times 10^{8}$ A. flavus conidia was injected underneath the husks into the side of the ear. Inoculum was prepared as described by Windham and Williams [21].

Ears were harvested approximately 60 days after inoculation and dried at $38^{\circ} \mathrm{C}$ for 7 days. Ears were then bulked together, shelled, mixed thoroughly and ground with a Romer mill (Union, MO, USA). Aflatoxin concentration in a 50-g sample was determined by the Vicam Aflatest (Watertown, MA, USA), which detects aflatoxin levels as low as $1 \mathrm{ng} / \mathrm{g}^{-1}$.

\subsection{Seed}

Seed for each experiment was obtained from the North Central Regional Plant Introduction Station (NCRPIS) in Ames, IA. The IITA-SRRC lines being tested were TZAR101, TZAR102, TZAR103, TZAR104, TZAR105 and TZAR106. Nurseries were used to increase seed and to create single cross hybrids involving the TZAR lines. Difficulties had occurred during the attempt to increase seed of 
TZAR105, which, therefore, was not tested in most trials. Crosses were made with PHW 79, 740, HBA 1, T 173, Va 35, B73, and LH132. These lines are all non-stiff stalk and are all susceptible to aflatoxin accumulation.

\subsection{Statistical Analysis}

The values for aflatoxin concentration were transformed before statistical analysis as $\operatorname{Ln}(y+1)$, where $y$ is the concentration of aflatoxin in a sample. Transformation was performed to stabilize the variance. All statistical analyses were conducted using the SAS software package (version 8.2; SAS Institute Inc., Cary, NC, USA). Data were analyzed with the PROC GLM procedure and means were separated using Fisher's protected least significant difference test at $p=0.05$. Aflatoxin data are reported as geometric means (antilog of the logarithmic mean) expressed in the original units of measure.

\section{Conclusions}

The limited evaluations of TZAR101-TZAR106 as germplasm lines and as single cross hybrids with several tester lines reported here, make it difficult to draw too many specific conclusions. Significant and dramatic reduction in aflatoxin accumulation compared to controls was definitely achieved by the IITA-SRRC inbred lines. Levels of aflatoxin concentration allowed in IITA-SRRC lines compared favorably with resistant lines that have been registered and released from Mississippi. However, further evaluation is needed in other areas of the south and elsewhere in the U.S. Studies investigating combining ability of these lines also need to be conducted. While germplasm line evaluations reported here and unreported data of testcross results indicate that TZAR106 may be superior in resistance to the other IITA-SRRC lines, more studies need to be conducted on all six lines before attention is focused on any particular line.

Acknowledgments: The authors thank M.N Alpe, P.M. Buckley, G.A. Matthews, L.T. Owens and P.L. Tranum of the USDA-ARS Corn Plant Host Resistance Research Unit technical staff at Mississippi State for their assistance with field management and harvest, and toxin preparation and analyses. Mention of trade names or commercial products in this manuscript is solely for the purpose of providing scientific information and does not imply recommendation or endorsement by the USDA. The authors acknowledge financial support from the Consultative Group for International Agricultural Research (CGIAR) Research Program 3.2: Maize-Global Alliance for Improving Food Security with the Livelihoods of the Resource-poor in the Developing World, 2012.

Author Contributions: R.L.B., A.M. and W.P.W. conceived and designed the experiments; G.W. performed the experiments; Z.Y.C. contributed analysis; R.L.B. wrote the paper.

Conflicts of Interest: The authors declare no conflict of interest.

\section{References}

1. Menkir, A.; Brown, R.L.; Bandyopadhyay, R.; Chen, Z.-Y.; Cleveland, T.E. A USA-Africa collaborative strategy for identifying, characterizing, and developing maize germplasm with resistance to aflatoxin contamination. Mycopathologia 2006, 162, 225-232. [CrossRef] [PubMed]

2. Brown, R.L.; Cotty, P.J.; Cleveland, T.E.; Widstrom, N.W. The living maize embryo influences accumulation of aflatoxin in maize kernels. J. Food Prot. 1993, 56, 967-971.

3. Brown, R.L.; Cleveland, T.E.; Payne, G.A.; Woloshuk, C.P.; Campbell, K.W.; White, D.G. Determination of resistance to aflatoxin production in maize kernels and detection of fungal colonization using an Aspergillus flavus transformant expressing Escherichia coli ß-glucuronidase. Phytopathology 1995, 85, $983-989$. [CrossRef]

4. Brown, R.L.; Chen, Z.-Y.; Menkir, A.; Cleveland, T.E. Proteomics to identify resistance factors in corn. Mycotoxin Res. 2006, 22, 22-26. [CrossRef] [PubMed]

5. Chen, Z.-Y.; Brown, R.L.; Damann, K.E.; Cleveland, T.E. Identification of unique or elevated levels of kernel proteins in maize genotypes resistant to aflatoxin production through proteomic analysis. Phytopathology 2002, 92, 1084-1094. [CrossRef] [PubMed] 
6. Brown, R.L.; Chen, Z.-Y.; Menkir, A.; Cleveland, T.E.; Cardwell, K.; Kling, J.; White, D.G. Resistance to aflatoxin accumulation in maize inbreds selected for ear rot resistance in West and Central Africa. Food Prot. 2001, 64, 396-400.

7. Chen, Z.-Y.; Brown, R.L.; Lax, A.R.; Guo, B.Z.; Cleveland, T.E.; Russin, J.S. Resistance to Aspergillus flavus in corn kernels is associated with a $14 \mathrm{kDa}$ protein. Phytopathology 1998, 88, 276-281. [CrossRef] [PubMed]

8. Menkir, A.; Brown, R.L.; Bandyopadhyay, R.; Chen, Z.-Y.; Cleveland, T.E. Breeding maize resistance to mycotoxins at IITA. In Mycotoxins: Detection Methods, Management, Public Health and Agricultural Trade; Leslie, J.F., Ed.; CABI Publishing: Wallingford Oxfordshire, UK, 2008; pp. 277-286.

9. Campbell, K.W.; White, D.G. Evaluation of corn genotypes for resistance to Aspergillus ear rot, kernel infection and aflatoxin production. Plant Dis. 1995, 79, 1039-1045. [CrossRef]

10. Menkir, A.; Brown, R.L.; Bandyopadhyay, R.; Cleveland, T.E. Registration of six tropical maize germplasm lines with resistance to aflatoxin contamination. J. Plant Regist. 2008, 2, 246-250. [CrossRef]

11. Kim, S.K.; Efron, F.; Khadr, F.; Fajemisin, J.; Lee, M.H. Registration of 16 maize streak virus resistant tropical maize parental inbred lines. Crop Sci. 1987, 27, 824-825. [CrossRef]

12. McMillian, W.W.; Widstrom, N.W.; Wilson, D.M. Registration of GT-MAS: Gk maize germplasm. Crop Sci. 1993, 33, 882. [CrossRef]

13. Scott, G.E.; Zummo, N. Registration of Mp420 germplasm line of maize. Crop Sci. 1991, 32, 1296. [CrossRef]

14. Scott, G.E.; Zummo, N. Registration of Mp313E parental line of maize. Crop Sci. 1990, 30, 1378. [CrossRef]

15. Williams, W.P.; Windham, G.L. Registration of maize germplasm line Mp715. Crop Sci. 2001, 41.4, 1374. [CrossRef]

16. Williams, W.P.; Windham, G.L. Registration of maize germplasm line Mp717. Crop Sci. 2006, 46.3, 1407-1408. [CrossRef]

17. Williams, W.P.; Windham, G.L. Registration of Mp718 and Mp719 germplasm lines of maize. J. Plant Regist. 2012, 6, 200-202. [CrossRef]

18. Williams, W.P.; Krakowsky, M.D.; Scully, B.T.; Brown, R.L.; Menkir, A.; Warburton, M.L.; Windham, G.L. Identifying and developing maize germplasm with resistance to accumulation of aflatoxins. World Mycotoxin J. 2015, 8, 193-209. [CrossRef]

19. Menkir, A.; Brown, R.L.; International Institute of Tropical Agriculture, Ibadan, Nigeria. Personal communication, 2014.

20. Zummo, N.; Scott, G.E. Evaluation of field inoculation techniques for screening maize genotypes against kernel infection by Aspergillus flavus in Mississippi. Plant Dis. 1998, 72, 313-316. [CrossRef]

21. Windham, G.L.; Williams, W.P. Evaluation of corn inbreds and advanced breeding lines for resistance to aflatoxin contamination in the field. Plant Dis. 2002, 86, 232-234. [CrossRef]

(C) 2016 by the authors; licensee MDPI, Basel, Switzerland. This article is an open access article distributed under the terms and conditions of the Creative Commons Attribution (CC-BY) license (http://creativecommons.org/licenses/by/4.0/). 